\title{
Papers
}

\section{Role of vaccinations as risk factors for ill health in veterans of the Gulf war: cross sectional study}

\author{
Matthew Hotopf, Anthony David, Lisa Hull, Khalida Ismail, Catherine Unwin, Simon Wessely
}

\begin{abstract}
Objectives To explore the relation between ill health after the Gulf war and vaccines received before or during the conflict. To test the hypothesis that such ill health is limited to military personnel who received multiple vaccines during deployment and that pesticide use modifies any effect. Design Cross sectional study of Gulf war veterans followed for six to eight years after deployment. Setting UK armed forces. Participants Military personnel who served in the Gulf and who still had their vaccine records. Main outcome measures Multisymptom illness as classified by the Centers for Disease Control and Prevention; fatigue; psychological distress; post-traumatic stress reaction; health perception; and physical functioning.

Results The response rate for the original survey was $70.4 \%(\mathrm{n}=3284)$. Of these, $28 \%$ (923) had vaccine records. Receipt of multiple vaccines before deployment was associated with only one of the six health outcomes (post-traumatic stress reaction). By contrast five of the six outcomes (all but post-traumatic stress reaction) were associated with multiple vaccines received during deployment. The strongest association was for the multisymptom illness (odds ratio 5.0; 95\% confidence interval 2.5 to 9.8 ). Conclusion Among veterans of the Gulf war there is a specific relation between multiple vaccinations given during deployment and later ill health. Multiple vaccinations in themselves do not seem to be harmful but combined with the "stress" of deployment they may be associated with adverse health outcomes. These results imply that every effort should be made to maintain routine vaccines during peacetime.
\end{abstract}

\section{Introduction}

Vaccines have been implicated as a possible cause of ill health in Gulf war veterans. Rook and Zumla hypothesised that the symptoms reported by veterans may be due to a shift in their $\mathrm{T}$ cell cytokine profiles from Th1 to Th2. ${ }^{1}$ They proposed that such a shift could be due to the regimen of vaccinations given to veterans and that this could lead to symptoms akin to those of chronic fatigue syndrome. In particular, they suggested that four aspects of the vaccination programme given to UK military personnel would increase the likelihood that they suffered long term health consequences. The first was that for UK (but not US) service personnel pertussis was used as an adjuvant to stimulate the immune response to anthrax vaccine. The second was that multiple vaccines were given simultaneously. This reflected the need to keep the personnel up to date with routine vaccines; to protect them from infectious diseases such as cholera and typhoid, which were potential health hazards during deployment; and to protect them from the threat of biological warfare agents-namely, plague and anthrax. The third aspect was that many of the vaccines were given after the personnel were deployed. Rook and Zumla suggested that deployment was a stress which would in itself lead to increased circulating corticosteroids, and this too would influence cytokine profiles. ${ }^{1}$ Finally, they speculated that there might have been an interaction between the vaccine regimen and pesticides-especially organophosphate pesticidesused in the Gulf to cause a Th2 promoting effect.

We have previously reported on a large $(n=3284)$ cohort study of male Gulf war veterans who were compared with non-deployed service personnel and veterans of peacekeeping duties in Bosnia. ${ }^{2}$ We found increased rates of ill health for all health outcomes in those who served in the Gulf. Among many other associations between exposures and health outcomes we found that servicemen who reported having multiple vaccines had a slightly increased risk of reporting multiple symptoms (odds ratio for seven or more vaccines 1.9). We also showed that pertussis vaccine was weakly associated with an increased risk of symptoms in service personnel who had their vaccine records (1.3). These two findings provide weak support for the first two of Rook and Zumla's hypothesised features of vaccine toxicity. ${ }^{1}$

We now report additional analyses to examine their second two hypotheses-namely, that multiple vaccines given at the time of deployment would be more likely to be associated with subsequent symptoms than those given before deployment. As the supposed mechanism for this putative effect was "stress," we also tested the hypothesis that the reporting of multiple stressful exposures during deployment would act as an effect modifier. We determined whether there was an interaction between reported pesticide use and the effect of multiple vaccines. Finally, we determined whether there was any association between vaccinations and other diseases

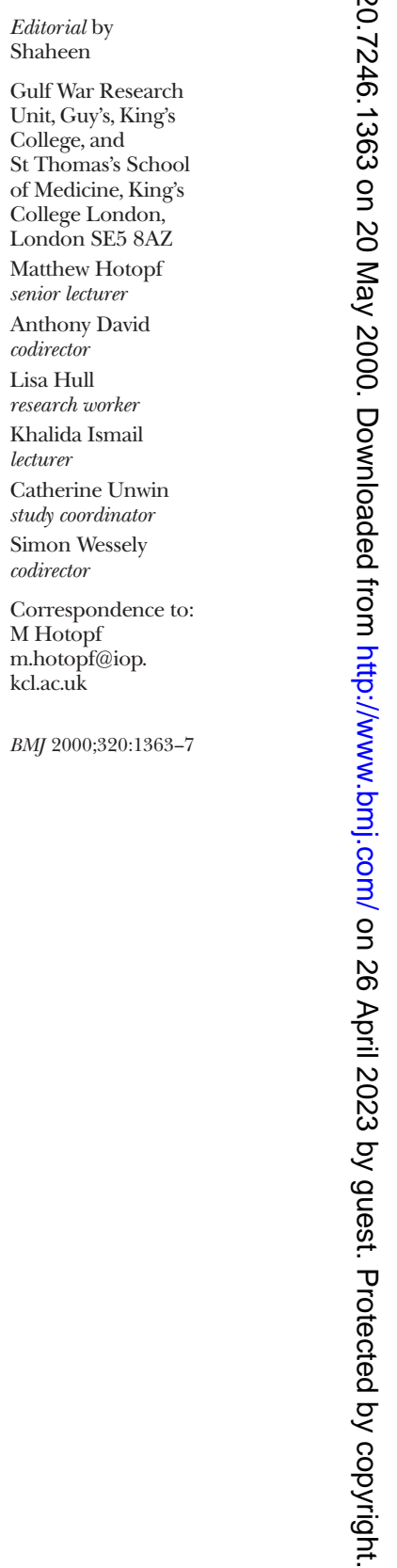


known to be associated with Th2 shifts-that is, the atopic illnesses: eczema, asthma, and hay fever.

\section{Methods}

Our original paper described the definition of the cohorts. ${ }^{2}$ For this study we used only servicemen who served in the Gulf $(n=3284)$. A comprehensive questionnaire was sent to members of this cohort, which was selected randomly from the target population of 53462 UK military personnel who went to the Gulf. Using three mailings, we obtained a response rate of $70.4 \%$. The questionnaire contained several measures of current health status, including a checklist of 50 symptoms and 39 medical disorders, the general health questionnaire (a measure of psychiatric morbidity ${ }^{3}$, a fatigue questionnaire, ${ }^{4}$ and two subscales of the SF-36 (a health status questionnaire)-health perception and physical functioning. ${ }^{5}$ Four outcomes (psychiatric morbidity, fatigue, health perception, and physical functioning) were therefore available. In addition we created two more outcomes-an approximation of the CDC multisymptom illness ("multisymptom illness") ${ }^{6}$ and an approximation of post-traumatic stress disorder ("post-traumatic stress reaction"). Participants were asked whether they had suffered from a number of medical conditions in the past year. These including asthma, hay fever, and eczema and psoriasis.

The main exposure data we used were self reported vaccines. Our questionnaire included details about whether the serviceman had his vaccine record, how many and which vaccines he received in the two months before deployment, and how many and which vaccines he received during deployment. In the original paper we showed that those who still had their vaccine records were considerably more likely to report having received pertussis at a level which closely matched the Ministry of Defence's own estimate. Because recall bias is a major problem in studies of Gulf war illness, for these analyses we used only the records of veterans who reported that they still had their vaccine records $(n=923)$. We asked service personnel to indicate whether they recalled being exposed to personal pesticides (for example, creams, sprays, or flea collars) or pesticides in their clothing or bedding. We also asked whether they had been exposed to a range of traumatic events, including witnessing someone dying, seeing maimed or seriously injured soldiers, and suffering combat related injuries.

We used logistic regression analysis to model the risk of ill health, defined as binary outcomes with increasing levels of vaccine exposure, controlling for the following potential confounders: age, officer status, service (Royal Navy, Army, Royal Air Force), and education. We used multiple regression to model the risk of ill health defined as continuous outcomes, including the same potential confounders. Likelihood ratio tests for trend were used to determine the strength of associations and effect modifiers. We performed additional analyses controlling for several other potential confounders. These confounders included all vaccines received; years in military service; reported side effects to vaccines; and date of deployment.

\section{Results}

Details on the response rate, differences between responders and non-responders, and basic sociodemography are presented in our previous paper. ${ }^{2}$ In all, $70.4 \%$ of Gulf veterans responded, and responders were more likely to be older, currently in service, and to have attended the Ministry of Defence's assessment programme for Gulf war veterans with symptoms. We included only those responders with vaccination records ( $\mathrm{n}=923 ; 28 \%$ of responders). We compared those with and without records of their vaccines and found no differences in educational status, rank, age, or health outcomes. The only difference of note was that those with records were more likely to have been reservists (for example, in the territorial army). Further analyses indicated that not seeing active service was not associated with any of the outcomes we used.

Table 1 shows the association between individual vaccines and the CDC syndrome according to whether the vaccines were given before or after deployment. The table shows firstly that the pattern of vaccines given before deployment was different from that given after deployment, with more "routine" vaccines and fewer biological warfare vaccines being received before deployment. The table gives odds ratios for the association between each vaccine and the multisymptom illness. Because receipt of each individual vaccine was not independent, we also put all vaccines into the same model. The only vaccines to be associated with the out-

Table 1 Association between receipt of individual vaccines before and after deployment in 923 veterans of the Gulf war and presence of multisymptom syndrome (Centers for Disease Control and Prevention)

\begin{tabular}{|c|c|c|c|c|c|c|}
\hline \multirow[b]{2}{*}{ Vaccine } & \multicolumn{3}{|c|}{ Before deployment } & \multicolumn{3}{|c|}{ After deployment } \\
\hline & $\begin{array}{l}\% \text { Of those } \\
\text { with records }\end{array}$ & $\begin{array}{l}\text { Adjusted }^{*} \text { odds ratio } \\
(95 \% \mathrm{Cl})\end{array}$ & $\begin{array}{l}\text { Adjusted† odds ratio } \\
(95 \% \mathrm{Cl})\end{array}$ & $\begin{array}{l}\% \text { Of those } \\
\text { with records }\end{array}$ & $\begin{array}{c}\text { Adjusted }{ }^{*} \text { odds ratio } \\
(95 \% \mathrm{Cl})\end{array}$ & $\begin{array}{c}\text { Adjusted† odds ratio } \\
(95 \% \mathrm{Cl})\end{array}$ \\
\hline Anthrax & 27.1 & 1.2 (0.9 to 1.6$)$ & $1.3(0.8$ to 2.0$)$ & 52.6 & 1.4 (1.0 to 1.8$)$ & $1.3(0.9$ to 2.0$)$ \\
\hline Plague & 8.2 & $1.2(0.7$ to 2.1$)$ & $1.2(0.6$ to 2.2$)$ & 27.6 & $1.2(0.9$ to 1.6$)$ & $0.9(0.6$ to 1.4$)$ \\
\hline Pertussis & 11.2 & $1.1(0.7$ to 1.7$)$ & $1.0(0.5$ to 1.7$)$ & 27.3 & 1.4 (1.0 to 1.9$)$ & $1.3(0.9$ to 2.0$)$ \\
\hline Tetanus & 32.8 & 1.0 (0.7 to 1.3$)$ & $0.9(0.6$ to 1.3$)$ & 3.8 & $2.9(1.2$ to 7.1$)$ & 2.7 (1.0 to 7.2$)$ \\
\hline Cholera & 29.8 & $1.0(0.7$ to 1.4$)$ & 0.9 (0.6 to 1.2$)$ & 3.1 & 2.6 (1.0 to 6.5$)$ & $2.9(1.0$ to 7.9$)$ \\
\hline Hepatitis A & 12.9 & $1.2(0.8$ to 1.8$)$ & 1.3 (0.8 to 2.1$)$ & 2.8 & 1.3 (0.6 to 3.1$)$ & 1.3 (0.5 to 3.2$)$ \\
\hline Hepatitis B & 9.3 & $0.8(0.5$ to 1.3$)$ & 0.8 (0.5 to 1.3$)$ & 4.9 & 0.9 (0.5 to 1.7$)$ & 0.7 (0.3 to 1.4$)$ \\
\hline Polio & 16.1 & $0.8(0.6$ to 1.2$)$ & 0.7 (0.5 to 1.2$)$ & 1.6 & $1.6(0.5$ to 5.2$)$ & $1.2(0.3$ to 4.3$)$ \\
\hline Yellow fever & 16.7 & $1.3(0.9$ to 1.9$)$ & $1.3(0.9$ to 1.9$)$ & 1.2 & 1.7 (0.4 to 6.6$)$ & 0.8 (0.2 to 3.7$)$ \\
\hline Typhoid & 28.6 & $1.1(0.8$ to 1.5$)$ & $1.0(0.7$ to 1.4$)$ & 2.8 & $1.3(0.5$ to 3.1$)$ & 0.7 (0.3 to 2.0$)$ \\
\hline
\end{tabular}

${ }^{*}$ Corrected for rank, age, service, and education.

†Corrected for rank, age, service, education, and all vaccines simultaneously. 
Table 2 Association between number of vaccines received before and during deployment

\begin{tabular}{lc}
$\begin{array}{l}\text { No of vaccines } \\
\text { before deployment }\end{array}$ & $\begin{array}{c}\text { Mean (median) No of } \\
\text { vaccines received during deployment }\end{array}$ \\
\hline $0-1$ & $3.5(3)$ \\
\hline 2 & $2.9(3)$ \\
\hline 3 & $2.6(2)$ \\
\hline 4 & $3.3(3)$ \\
\hline $5+$ & $3.0(3)$ \\
\hline
\end{tabular}

come were tetanus and cholera when they were given during deployment. This, however, represented a relatively small group of veterans with records $(3.8 \%$ and $3.1 \%$ respectively).

There was no relation between the number of vaccines received before deployment and the numbers received during deployment (table 2). Receipt of multiple vaccines either before or during deployment was not associated with age, education, or rank. Those in the army were more likely to receive multiple vaccines after deployment than Naval or Air Force personnel $(\mathrm{P}=0.07)$. There was an association between receipt of multiple vaccines both before and during deployment and being in the medical corps. In total $34.5 \%$ of those who received multiple vaccines before deployment were deployed between August and December 1990, whereas $70.3 \%$ of those receiving multiple vaccines after deployment were deployed during this time.
Table 3 shows the association between multiple vaccines and all six health outcomes, depending on whether the vaccines were received before or during deployment. For only one health outcome (posttraumatic stress reaction) was there any association with receipt of multiple vaccines before deployment. For receipt of multiple vaccines after deployment, however, the situation was reversed-five of the six outcomes (all except post-traumatic stress reaction) were associated. The effects were particularly striking for the multisymptom illness.

We used a series of additional analyses to determine whether the association between multiple vaccines during deployment could be accounted for by possible confounders. Firstly, we hypothesised that the effect might be due to the influence of individual vaccines. We therefore controlled for all vaccines received simultaneously (table 4 ). This did not affect the relation. Secondly, we thought that those most likely to receive multiple vaccines simultaneously would be the service personnel who had only recently joined the forces as those with more experience and previous deployments would be less likely to need new vaccines. If previous experience of deployment was protective of the health effects of going to the Gulf this could account for the relation; however adjustment for years in the military made no difference. We also controlled for the experience of side effects to vaccines,

Table 3 Association between six health outcomes and multiple vaccines depending on deployment. All odds ratios and mean differences are controlled for education, age, service (Royal Navy, Army, or Royal Air Force), and rank (commissioned officer, other ranks). Statistical test results are trend tests

\begin{tabular}{|c|c|c|c|c|c|c|c|}
\hline $\begin{array}{l}\text { No of } \\
\text { vaccines }\end{array}$ & $\begin{array}{l}\text { No } \\
\text { receiving } \\
\text { vaccine }\end{array}$ & $\begin{array}{c}\text { Odds ratio }(95 \% \mathrm{Cl}) \\
\text { for multisymptom } \\
\text { illness }\end{array}$ & $\begin{array}{l}\text { Odds ratio } \\
(95 \% \mathrm{Cl}) \text { for } \\
\text { fatigue case }\end{array}$ & $\begin{array}{l}\text { Odds ratio }(95 \% \mathrm{CI}) \\
\text { for multisymptom } \\
\text { illness (GHQ case }{ }^{\star} \text { ) }\end{array}$ & $\begin{array}{c}\text { Odds ratio (95\% Cl) } \\
\text { multisymptom } \\
\text { illness (PTSR case†) }\end{array}$ & $\begin{array}{c}\text { Mean difference } \\
(95 \% \text { Cl) for health } \\
\text { perception¥ }\end{array}$ & $\begin{array}{c}\text { Mean difference } \\
(95 \% \text { Cl) for physical } \\
\text { functioning }\end{array}$ \\
\hline \multicolumn{8}{|c|}{ Before deployment } \\
\hline $0 / 1$ & 157 & 1.0 & 1.0 & 1.0 & 1.0 & - & - \\
\hline 2 & 142 & 1.0 (0.6 to 1.6$)$ & 1.1 (0.7 to 1.8 ) & 1.0 (0.6 to 1.7$)$ & 0.9 (0.4 to 2.1$)$ & $-3.9(-9.6$ to 1.9$)$ & $-1.2(-4.2$ to 1.8$)$ \\
\hline 3 & 122 & $0.8(0.5$ to 1.4$)$ & 0.8 (0.5 to 1.3$)$ & $0.9(0.5$ to 1.6$)$ & $1.3(0.6$ to 3.0$)$ & $1.6(-4.4$ to 7.7$)$ & $1.8(-1.4$ to 4.9$)$ \\
\hline 4 & 131 & 1.3 (0.8 to 2.2$)$ & $1.2(0.7$ to 2.0$)$ & 1.6 (1.0 to 2.7 ) & $2.0(0.9$ to 4.4$)$ & $-4.8(-10.7$ to 1.1$)$ & $-1.7(-4.8$ to 1.4$)$ \\
\hline \multirow[t]{2}{*}{$\geqslant 5$} & 74 & $1.1(0.6$ to 2.0$)$ & 1.2 (0.7 to 2.2$)$ & $1.1(0.6$ to 2.1$)$ & $2.2(0.9$ to 5.2$)$ & $-3.3(-17.3$ to -1.9$)$ & $-2.7(-6.4$ to 1.1$)$ \\
\hline & & $\chi^{2}=00.7(0.38)$ & $\chi^{2}=0.6(0.45)$ & $\chi^{2}=2.0(0.16)$ & $\chi^{2}=6.3(0.01)$ & $\mathrm{t}=1.1(0.3)$ & $\mathrm{t}=1.2(0.21)$ \\
\hline \multicolumn{8}{|c|}{ During deployment } \\
\hline $0 / 1$ & 193 & 1.0 & 1.0 & 1.0 & 1.0 & - & - \\
\hline 2 & 103 & 2.2 (1.3 to 3.7$)$ & $1.8(1.1$ to 3.0$)$ & $1.1(0.7$ to 1.9$)$ & $1.6(0.7$ to 3.7$)$ & $-7.3(-13.3$ to -1.3$)$ & $-2.6(-5.8$ to 0.7$)$ \\
\hline 3 & 108 & $2.4(1.4$ to 4.0$)$ & $1.8(1.1$ to 2.9$)$ & $1.6(0.9$ to 2.6$)$ & 3.0 (1.4 to 6.5$)$ & $-8.9(-14.7$ to -3.0$)$ & $-2.6(-5.8$ to 0.5$)$ \\
\hline 4 & 172 & 2.2 (1.4 to 3.4$)$ & $2.0(1.3$ to 3.0$)$ & $1.2(0.8$ to 1.9$)$ & $1.7(0.8$ to 3.5$)$ & $-5.9(-11.0$ to -0.8$)$ & $-2.2(-5.0$ to 0.6$)$ \\
\hline \multirow[t]{2}{*}{$\geqslant 5$} & 70 & 5.0 (2.5 to 9.8$)$ & 3.4 (1.9 to 6.2$)$ & 2.1 (1.2 to 3.7$)$ & $1.9(0.8$ to 4.7$)$ & $-15.0(-21.8$ to -8.2$)$ & $-6.3(-10.0$ to -2.6$)$ \\
\hline & & $\chi^{2}=24.9(<0.0001)$ & $\chi^{2}=16.7(<0.0001)$ & $\chi^{2}=4.81(0.03)$ & $\chi^{2}=2.4(0.12)$ & $t=3.8(<0.001)$ & $\mathrm{t}=287(0.005)$ \\
\hline
\end{tabular}

${ }^{*}$ General health questionnaire

tPost-traumatic stress reaction.

$\ddagger$ Mean differences refer to decrements in percentage points on SF-36 subscales.

Table 4 Association between multiple vaccines during deployment controlled for three additional potential confounders. Figures are odds ratios (95\% confidence intervals) for multisymptom illness

\begin{tabular}{|c|c|c|c|c|}
\hline \multirow[b]{2}{*}{$\begin{array}{l}\text { No of vaccines } \\
\text { during } \\
\text { deployment }\end{array}$} & \multicolumn{4}{|c|}{ Correction } \\
\hline & All vaccines received & $\begin{array}{l}\text { All vaccines received, } \\
\text { No of years in military }\end{array}$ & $\begin{array}{l}\text { All vaccines received, } \\
\text { No of years in military, } \\
\text { reported side effects }\end{array}$ & $\begin{array}{l}\text { All vaccines received, } \\
\text { No of years in military, reported side effects, } \\
\text { month of deployment, total duration in theatre }\end{array}$ \\
\hline $0 / 1$ & 1.0 & 1.0 & 1.0 & 1.0 \\
\hline 2 & $2.8(1.5$ to 5.2$)$ & $2.5(1.5$ to 4.2$)$ & $1.9(1.1$ to 3.2$)$ & $2.9(1.5$ to 5.6$)$ \\
\hline 3 & $3.5(1.8$ to 6.8$)$ & $2.6(1.5$ to 4.3$)$ & $2.0(1.2$ to 3.3$)$ & $2.4(1.3$ to 4.7$)$ \\
\hline 4 & $3.5(1.8$ to 6.8$)$ & $2.3(1.5$ to 3.6$)$ & 1.7 (1.1 to 2.7$)$ & 2.5 (1.4 to 4.6$)$ \\
\hline \multirow[t]{2}{*}{$\geqslant 5$} & 8.6 (3.5 to 21.0$)$ & $5.5(2.7$ to 11.1$)$ & $4.1(2.1$ to 8.2$)$ & $7.3(3.1$ to 17.5$)$ \\
\hline & $\chi^{2}=21.4(<0.0001)^{*}$ & $\chi^{2}=26.7(<0.0001)^{*}$ & $\chi^{2}=14.0(0.0002)^{*}$ & $\chi^{2}=17.3(<0.0001)^{*}$ \\
\hline
\end{tabular}

${ }^{\star}$ Test for trend with $\mathrm{P}$ value. 
Table 5 Association between multiple vaccines and atopic conditions. Figures are odds ratios (95\% confidence intervals)

\begin{tabular}{|c|c|c|c|c|}
\hline $\begin{array}{l}\text { No of } \\
\text { vaccines }\end{array}$ & $\begin{array}{l}\text { No receiving } \\
\text { vaccine }\end{array}$ & Asthma & Hay fever & Eczema or psoriasis \\
\hline \multicolumn{5}{|c|}{ Before deployment } \\
\hline $0 / 1$ & 157 & 1.0 & 1.0 & 1.0 \\
\hline 2 & 142 & 0.9 (0.3 to 2.4$)$ & 0.7 (0.4 to 1.2$)$ & $0.8(0.3$ to 1.9$)$ \\
\hline 3 & 122 & $0.5(0.1$ to 1.6$)$ & $0.9(0.5$ to 1.6$)$ & 1.4 (0.6 to 3.2$)$ \\
\hline 4 & 131 & $1.0(0.4$ to 2.7$)$ & $0.9(0.5$ to 1.7$)$ & $1.1(0.5$ to 2.7$)$ \\
\hline \multirow[t]{2}{*}{$\geqslant 5$} & 74 & $1.0(0.3$ to 3.2$)$ & $1.0(0.5$ to 1.9$)$ & $1.4(0.6$ to 3.8$)$ \\
\hline & & $\chi^{2}=0.00(0.99)$ & $\chi^{2}=0.06(0.81)$ & $\chi^{2}=0.93(0.3)$ \\
\hline \multicolumn{5}{|c|}{ During deployment } \\
\hline $0 / 1$ & 193 & 1.0 & 1.0 & 1.0 \\
\hline 2 & 103 & $2.4(0.8$ to 7.6$)$ & $1.6(0.9$ to 2.9$)$ & $2.2(1.0$ to 4.9$)$ \\
\hline 3 & 108 & $2.2(0.7$ to 7.0$)$ & $1.3(0.7$ to 2.3$)$ & $1.0(0.3$ to 2.5$)$ \\
\hline 4 & 172 & $2.3(0.8$ to 6.6$)$ & $0.9(0.5$ to 1.6$)$ & $0.9(0.4$ to 2.1$)$ \\
\hline \multirow[t]{2}{*}{$\geqslant 5$} & 70 & $3.3(1.0$ to 10.8$)$ & $1.4(0.7$ to 2.8$)$ & $1.7(0.7$ to 4.4$)$ \\
\hline & & $\chi^{2}=3.5(0.06)$ & $\chi^{2}=0.01(0.94)$ & $\chi^{2}=0.01(0.92)$ \\
\hline
\end{tabular}

and this led to a reduction in the odds ratios, but the relation still remained. We controlled for the month of deployment and total duration of deployment to the Gulf-clearly those who were deployed early and stayed late were more likely to receive vaccines during deployment and may have been at higher risk of ill health because of their more prolonged service experience. This, however, increased the effect size. We did additional analyses to control for smoking and alcohol consumption, but these potential confounders had no effect on any of the trends reported. Finally, we controlled for the total number of stressful events reported. This led to a loss of the association between vaccines after deployment and being classified as a case on the general health questionnaire $\left(\chi^{2}=2.1 ; \mathrm{P}=0.14\right)$ and a reduction in the association between posttraumatic stress reaction and vaccines before deployment to marginal significance $\left(\chi^{2}=3.62 ; \mathrm{P}=0.06\right)$.

No interaction terms were found for relations between multiple vaccines after deployment and the number of traditional combat stressors $\left(\chi^{2}=2.64\right.$; $\mathrm{df}=1 ; \mathrm{P}=0.10)$ or self reported pesticide use $\left(\chi^{2}=0.2\right.$; $\mathrm{df}=1 ; \mathrm{P}=0.66$ ).

Finally, table 5 shows the association between vaccines and atopic conditions. There was no association between vaccination before deployment and any of these outcomes. There was, however, an association between vaccines after deployment and asthma. The total number of sufferers was small so the confidence intervals are wide, and the result is of only marginal significance. There was no such association for the other atopic conditions.

\section{Discussion}

Our findings provide partial support for the hypothesis of Rook and Zumla. ${ }^{1}$ Multiple vaccinations in military personnel in the Gulf war were associated with subsequent ill health only in servicemen who received vaccines after deployment. Traditional stresses of war, however, did not modify the effect of multiple vaccines, and there was no interaction between vaccines and the use of pesticides.

\section{Methodological concerns}

It is necessary to consider some general limitations of this study. Firstly, we limited the sample to a group of servicemen who had kept their vaccine records. Most exposures we have reported on previously have relied entirely on self reports from servicemen and are thus prone to recall bias. We reasoned that the group with vaccine records would be able to give a more accurate picture of the vaccines they had received and, because timing of vaccines was crucial to the question under study, we limited the analyses to this group. They may have been an unusual group, but we could not detect any differences between them and the other servicemen, including their health outcomes. Analysis of our entire sample of veterans (not reported) did not show such a clear cut pattern-multiple vaccines were associated with ill health no matter when they were given.

There were probably several reasons why some veterans received vaccines during the conflict rather than before it. When we assessed broad demographic and occupational differences in servicemen who received multiple vaccines before rather than during the conflict, however, there were few differences. As expected, those who received vaccines during deployment tended to have been deployed earlier, and medical personnel tended to report more vaccines-which may indicate more accurate reporting by them as well as more vaccines required for occupational needs, such as hepatitis B. Other potential confounders-such as years of previous service in the military and the individual vaccines received-did not substantially alter our estimates of effect, but reports of side effects after vaccination led to a reduction in the association. Initial symptoms could "sensitise" individuals to later symptoms or perhaps initial symptoms indicated differences in biological response. Alternatively, there may be a general reporting bias whereby those who experience side effects also report more symptoms at follow up.

The reliability of ascertainment of vaccine history requires some comment. We were asking veterans to report on vaccines they had received six to eight years before. We did not have their actual records but asked them to transfer details from their records to our questionnaire. Thus it is possible that our measures of total vaccines received are inaccurate. Recall bias may have affected our results. The difference in effects we found between multiple vaccines given before the conflict as opposed to vaccines given during deployment to such generalised and non-specific complaints of ill health, however, is difficult to explain on the basis of recall bias alone. Our previous paper showed that practically all exposures were associated with nearly all outcomes ${ }^{2}-\mathrm{a}$ general non-specific pattern which could be expected if recall bias played a part. In this paper, the absence of an association with vaccines before deployment is in itself remarkable.

\section{Possible mechanisms}

If bias and confounding are not considered important explanations, what pathways could link multiple vaccines given during deployment to subsequent ill health? Firstly, Rook and Zumla's hypothesis may be correct. ${ }^{1}$ We have not as yet, however, performed the immunological investigations that would test this directly. Animal models have also failed to find any behavioural consequences of high dose multiple vaccines. $^{7}$ 
Furthermore, the hypothesis is partly based on the assumption that the immunology of chronic fatigue syndrome is consistent and well understood, whereas the experience from the multitude of published studies suggests that this is far from the case. ${ }^{8}$ Secondly, there may be alternative mechanisms. We found that controlling for the experience of side effects led to a substantial reduction in the association between multiple vaccines and ill health. Our measure of vaccine side effects was crude (a single question), and a degree of residual confounding may be present. It may be that multiple vaccines cause an increased risk of side effects and these reactions-which are usually self limitinggain new salience in settings of stress, such as being deployed to the Gulf.

We failed to find any interaction between vaccines and either traditional military stressors or pesticide use. The lack of an association with military stressors does not necessarily indicate that there is no interaction between stress and vaccines. Such military stressors may be less important for trained service personnel than the general stress associated with deployment, which includes change of climate, living conditions, diet, sleepwake pattern, and physical activity as well as fears over personal safety and separation from one's family. The measurement of pesticide use was crude and relied on self report. In addition we may not have had sufficient statistical power to detect an interaction term.

\section{Implications}

What are the implications of our findings for future conflicts? It would be folly to allow service personnel to be committed to a modern battlefield without all necessary means of protection against endemic infection and biological weapons. The main such protection is vaccination. Our findings are compatible with a link between multiple vaccines given at the time of deployment and subsequent illness. They also suggest a measured intervention-with every effort made to ensure that soldiers either maintain routine vaccinations (including biological warfare vaccines) or at least that even in the inevitable crisis atmosphere of deployment, early vaccination with as long a gap as possible before the actual stress of deployment-would be prudent. The critical constituents of this "stress" require urgent study. Finally, our results should be viewed only in the narrow context of service personnel deployed to

\section{What is already known on this topic}

Military personnel who served in the Gulf war have higher rates of non-specific symptoms than other military populations

Multiple vaccines may be weakly associated with this outcome What this study adds

There was a specific association between the timing of multiple vaccines and ill health: personnel who received multiple vaccines before deployment were not at increased risk, whereas those who had received them during deployment were

Vaccines, however, are only one of the many exposures implicated

Pesticides do not seem to interact with vaccines to cause ill health

the Gulf war. The combination of multiple vaccines before deployment seems safe, and this study provides no evidence that vaccine regimens currently used in civilians are harmful.

We are grateful to Mr Nick Blatchley and Dr Martin Prince for their comments on an earlier draft.

Contributors: $\mathrm{MH}$ was responsible for framing the hypotheses, analysing the results, and writing the paper and is its guarantor. $\mathrm{AD}$ and $\mathrm{SW}$ were principal investigators for the study. $\mathrm{CU}$ was the study coordinator. LH and KI assisted in study design, data collection, and writing up.

Funding: United States Department of Defence.

Competing interests: None declared.

1 Rook GAW, Zumla A. Gulf war syndrome: is it due to a systemic shift in cytokine balance towards a Th2 profile? Lancet 1997;349:1831-3.

2 Unwin C, Blatchley N, Coker W, Ferry S, Hotopf M, Hull L, et al. Health of UK servicemen who served in the Persian Gulf War. Lance 1999;353:169-78

3 Goldberg D. The detection of psychiatric illness by questionnaire. London: Oxford University Press, 1972.

4 Chalder T, Berelowitz C, Pawlikowska T. Development of a fatigue scale. Psychosomatic Res 1993;37:147-54.

5 Stewart AD, Hays RD, Ware JE. The MOS short-form general health survey. Medical Care 1988;26:724-32

6 Fukuda K, Nisenbaum R, Stewart G, Thompson WW, Robin L, Washko $\mathrm{RM}$, et al. Chronic multisymptom illness affecting air force veterans of the gulf war. JAMA 1998;2809:981-8.

7 Griffiths GD, Hornby RJ, Stevens DJ, Scott L, Upshall D. Consequence of multiple vaccination with pyridostigmine pretreatment in the guinea pig-a multi-parameter study. Conference on federally sponsored Gulf war veteran's illmulti-parameter study. Conference on federally sponsored

8 Wessely S, Hotopf M, Sharpe M. Chronic fatigue and its syndromes. Oxford: Oxford University Press, 1998.

(Accepted 7 February 2000)

\title{
One hundred years ago
}

\section{The war in South Africa: The hot dry summer}

\begin{abstract}
Mr. Frederick Treve's letter from Freer Camp, which appeared in the last issue of the BRITISH MEDICAL JOURNAL, has been read with the greatest interest both by the medical profession and the public. His graphic descriptions of the little town and the parched brown veld of the African summer are admirable, and bring before us, as scarcely any other correspondent has done, a picture of the camp, "dry, dusty, parched, and restless under a blazing sun." The heat both at Frere Camp and in Ladysmith itself appears to have been great, even for an African summer. Thus Mr. Treves says that on one day it was $104^{\circ}$ in the shade, and that a clinical thermometer in a bag lying in the tent registered $104.5^{\circ}$.

A despatch from Ladysmith by runner, dated January 21st, states among other things that the heat was $107^{\circ}$ in the shade. A heat of this degree does, however, not infrequently occur during
\end{abstract}

the summer months in the up-country towns of South Africa. Thus in Kimberley I have known the temperature over $100^{\circ} \mathrm{F}$, in the shade daily for weeks together. With such weather as this it is of course usual, and in fact almost necessary, in the normal condition of life, that people should remain almost entirely under shelter during the middle hours of the day; yet we read of our soldiers in one engagement after another exposed to the blazing sun throughout the entire day. Fortunately in the dry atmosphere of South Africa these extreme temperatures are not so oppressive as in moister climates; nevertheless a temperature of $100^{\circ}$ in the shade means something a great deal higher in the actual sun, and where the sunlight actually falls on the body it produces a sensation almost as if one were being hit by a stick.

(BMJ 1900;i:280) 